\section{CASES OF THE FURTHER SUCCESS OF THE READY METHOD.}

To the Editor of THE LANCET.

SIR, - I think the following lines, which comprise further details of the case of Narcotic Poisoning, and of a case of Drowning, will have gneat value for the readers of THE LANCET, and I trust they may occupy an early place in its pages.

I am, Sir, your obedient servant,

March, 1857 Marshalit hali.

60, New-street, St. Helier's, Jersey, Feb. 10th, 1857

DeAr Sir, - Truly has it been said that medicine in judicious hands is the handmaid of Nature.

As truly may it be said that your thoughtful and ingenious application of great principles and natural laws to the treatment of diseases and accidental exigencies must be ranked amongst one of the great discoveries of modern medical science; for they have since the short period of their first promulgation been the means of saving many lives that would have been otherwise lost.

The enclosed I have thought worthy of record, as exemplifying in a remarkable degree the truth of the principle as well as the success of the "Marshall Hall Method."

The desire of adding testimony to a great truth, which like all others is too slow in being received and appreciated, and the wish of seeing honour given to whom it is due, are the only apologies I have to offer for addressing you. Believe me to be, Sir, yours very truly, Dr. Marshall Hall. Gharles VAUDIN, M.R. C.S., \&c.

Mrs. D-, a lady of exceedingly delicate constitution, aged twenty-six, was taken in labour of her second child on the 2nd of January at seven A.M. She had suffered trifling pains two days before, and had not felt the motion of the child since they commenced. I saw her at nine, and found her then suffering from frequent but ineffectual pains. The vagina and external parts were hot and dry; the os uteri dilated to the extent of a shilling; its lips thin, dry, and unyielding; membranes entire; and head presenting. A careful stethoscopic examination of the abdomen failed to detect any sounds of the fœtal heart. The pelvis was small, but not deformed.

At seven P.M. on the 3rd, I delivered her of a delicate male child. Around its neck were two folds of the funis, in which I could not detect the slightest pulsation. It was cut and lightly ligatured. The surface was flaccid, cold, and very livid; the lips blue; the palms, soles, and a small surface over the nates were quite sodden, and partially exfoliated. Fintire absence of all reflex action. The pupils were insensible to light, the nose to ammonia, and there was not the slightest appreciable motion in the præcordial region. The usual remedies, except sufflation and the hot bath, were tried without success. Suspended animation could hardly be more pronounced or akin to death.

The "Marshall Hall Method" I persevered in for twenty-six minutes, accurately noted by my watch before me. The postural movements were made upon warm blankets frequently changed. Then the funis began to bleed; about one drachm of blood was lost, and it was secured. The countenance had before this undergone a marked change, had become mottled and red. My observations of the respiratory action coincided exactly with Mr. M. H. Higginbottom's - viz. " with each induced expiration a quantity of air, denoted by bubbles of a tenacious frothy mucus, issued from each nostril, the bubbles receding on ind uced respiration." I could now distinctly discover a slight fluttering action of the heart. After twenty-nine minutes, and following an induced expiration, I noticed a tremour of the skin and muscles over the epigastrium, followed by a sudden voluntary inspiration, the chest becoming forcibly distended and fixed, rendering its diaphragmatic boundary tense, and, as well as itself, resonant as a drum all over. 'The chest remained in this fixed position for nearly two minutes, the intercostal muscles being very prominent, the postural motions still going on, and I began to think all my efforts ended here, when the child made a voluntary expiration, attended by a cry; the movements and frictions were made with redoubled energy, and I soon had the gratification of hearing the infant cry loudly enough, and breathe alone, as well as empty its bladder vigorously, thirty-three minutes having elapsed. The door and a window of the room were kept open, and the process carried on near the former to ensure a supply of fresh air. The child has subsequently been dry nursed, and is doing well.
Wiveliscombe, Somerset, Feb. 6th, 1857.

DeAR SIR, - With much pleasure and satisfaction I send you very short account of a case of asphyxia in a new-born infant treated by your invaluable plan.

On Tuesday, Feb. 3rd, at four P.M., I was called some miles through frost, snow, \&c., to a poor woman who had been in labour three days, and who, strange to say, out of eight labours, has five times had arm presentations and twice placenta prævia. I found part of the placenta and both arms presenting, and after very great exertions, delivered her by turning of an apparently dead child. For three or four minutes I was so much engaged with the mother, who was in a state of great prostration, that the child was not attended to. I then treated the child on your plan, although with very faint hope of success; but after rather more than half an hour's exertions, much to my satisfaction, and to the nurse's and mother's astonishment, circulation and respiration were as strong as $I$ ever saw in a new-born child. I feel quite sure that hot water, friction, brandy, \&c., would have been useless in this case.

Mr. M. H. Higginbottom's case was very much like mine, as I noticed the frothy mucus which came from the nostrils, and this gave me great trouble as the nurse would give me no help in a case which she thought hopeless. I may add that I saw the little patient this morning; and she is as strong as any child of three days old.

The weather was very cold, and I quite think with you that cold protracts latent vitality, and gives you a greater chance in these cases.

I am, dear Sir, yours very truly,

Marshall Hall, M.D., F.R.S. James Nicholls, M.D.

Tattershall, Feb. 28th, 1857.

DEAR SIR, - I have much pleasure in complying with your request for the details of my case of poisoning.

On making inquiries of the relatives of my little patient, I learnt that it had been for the last few days suffering from a cough, and that they had given it a sufficient quantity of poppy-water to compose it to sleep. It slept all night and the following morning without intermission, when, about twelve o'clock A. M., on attempting to give it some broth, it was seized with a fit, to relieve which it was placed in a warm bath, but was soon removed from thence, apparently lifeless.

On my arrival at the house, a little before two o'clock P.M., I found the child lying in its grandmother's arms, in a state of insensibility; the eyes were closed, the pupils contracted; no pulse and no respiration could be detected.

I immediately placed it in the prone position, with one hand under its forehead, the other under the chest. I commenced turning the body on the side and a little beyond, and then on the face, alternately, repeating these measures thirteen or fourteen times in a minute; at the same time, the attendants were desired to rub the limbs upwards simultaneously.

I had not continued my attempts at resuscitation more than a few minutes, when a slight motion of the brain became perceptible, and gasping movements of the mouth followed.

Although no decided amendment displayed itself for some time, yet I was fully convinced that the efficient maintenance of the respiratory process was of the first importance, not only to the continuance of the circulation, but also as being the chief means by which the poison is eliminated. I therefore persevered in the postural movements until half-past six the same evening before I could pronounce my patient out of danger.

Apologizing for not replying to your note earlier,

Dr. Marshall Hall.

$$
\text { I remain, your obedient servant, }
$$

Charles Buades.

Newport, Isle of Wight, March 13th, 1857.

MY DEAR SIR, - T have adopted your discovery in several cases with perfect success.

A female, aged thirty-two, in a moment of rage, threw herself from a bridge into our river. I was not perfectly satisfied that the asphyxiated condition in which I found her arose from drowning-although it might have done so-because the depth of water was not above the knees. Some of the parties who picked her up said she was not long enough in the water to be drowned; others said she was drowned. I attributed the apnoa to the shock to the neryous system produced by the fall from the height, from firteen to twenty feet-she pitched on the nates; or to the exposure to cold, it being a bitter night, and she was dragged a long distance in the water to reach the landing-place. It might perhaps arise from combined causes.

I was soon on the spot, and in the language of the bystanders found her dead, in other terms, asphyxiated. I commenced 
your Ready Method, and continued it for upwards of an hour, with perfect success, to the amazement of her friends who assisted me.

The other cases were suspended animation from childbirth, of which so many cases are on record.

I shall be happy to reply to any questions on the foregoing case, if you may desire further information.

Believe me, with sincere respect, faithfully yours, Dr. Marshall Hall. EnNest P. WILKINS.

To the Editor of The LaxceT.

SIR, - Within the last three weeks I have had two opportunities of trying the Ready Method in the asphyxia of newlyborn infants. One was a case of turning on account of armpresentation; the other was a presentation of the breech. In both instances the heart's action was barely perceptible; no pulsation could be felt in the cord, and no inspiratory effort could be detected. After rotating the trunk five or six times, inspiration commenced, and in a short time respiration became fully established, so that the children were able to cry vigorously. I purposely abstained from using any other means of resuscitation. My experience of these two cases would, as far as it goes, lead me to consider Dr. Marshall Hall's method as far more prompt and effectual than any of the means which we had previously been accustomed to nse.

I am, Sir, your obedient servant, J. G. Swayne

Physician-Accoucheur to the Bristol General Hospital, and Lecturer on Midwifery at tine

Clifton, MIâreh, 1857. Bristol Medical School.

\section{THE DENTISTS AND THE COLLEGE OF SURGEONS.}

\section{To the Editor of THE LANCET.}

Sir,--I believe there is a general opinion among members of the College of Dentists and of the Odontological Socjety that an amalgamation of the two bodies, into which unfortunate differences of opinion have divided the profession, would be an advantage to all parties concerned. This is decidedly my opinion, as a member of the College of Dentists, which institution I have warmly supported from the first. But there are diffculties in the way leading to such an amalgamation which at first sight appear almost insurmountable. Let us see what these difficulties are, and consider whether they may not be overcome, or at least lessened.

First of all (a desire to come to an amicable arrangement ment having become developed), how is negotiation between the two bodies to be establis'.ed? The College of Dentists was the first planned; in point of numbers it is as three to one of the Odontological Society; and as the resulations are of a nature to exclude all but legitimate practitioners, it would be invidious even to consider the members (taken as a whole) of inferior siculus. An offer of negotiation, then, caunot be expected from the College. The Odontological Society would probably think it derogatory to take the initiative; if so, what is to be done? You, Sir, have suggested that a third party might step in between the two, hold ont a hand to each, and so bring them together. In this suggestion I cordially concur, but am of opinion that instead of the third party being composed of medical practitioners, it should be represented in the persons of those dentists who have as yet held aloof from either movement; such men, for instance, as Mr. Bell, Mr. Clendon, and others.

The next (and probably the greatest) difficulty is, as to the officers and council of the amalgamated bodies. I cannot, however, but think that there is a sufficient amount of genuine good sense in the councils of both to come to a satisfactory arrangement even in this particular.

We now come to what shall be the governing principle of the new institution. The College of Dentists would be an independent body; the Odontological Society would establish a connexion with the College of Surgeons. These views seem antagonistic to each other, but by mutual concessions it might be found that a College of Dentists would exist independently of the College of Surgeons, although a certificate of proficiency in surgery, \&c., from a board of examiners to be nominated by the College of Surgeons, should be required by the College of Dentists before granting their diploma.

I think there remains but one other difficulty, of any moment, to be mentioned: What is to be done with the associates in connexion with the College of Dentists? If there was serious objection to their being received in their present capacity into the new Society, how are we to proceed? I can only reply that I believe the associates of the College of Dentists are, every one of them, too unselfish to wish to throw any obstacle in the way of an amalgamation, although I must confess that I think they have a perfect right to claim consideration in any arrangements that may be come to.

In conclusion, Sir, I can only repeat that I should hail with delight a reconciliation of the profession, and, as an individual member of the College of Dentists, do my best to promote it; although nothing would induce me to consent to any proceedings calculated to weaken the influence of the College, the manner of the first formation of which can be looked back npon by all connected with it with so much pride and satisfaction. - I am, Sir, your obedient servant,

Mareh, $185 \tilde{T}$

A Member of the COLlege of Dentists.

I enclose my card.

\section{THE "ECCENTRIC PROCEEDING" AT EDIN- BURGH.}

To the Editor of THE LANCET.

Sir,-As many members of the Royal Medical Society consider themselves to have been unjustly dealt with in some remarks that fell from your Edinburgh correspondent regarding the "blackballing" of Professor Bennett and MM. Bernard and Brown-Séqnard, I have thought it but fair to place the proceedings in a proper light. Your correspondent designates the affair an "eccentric proceeding," and if it were true that anything like a majority of the members "blackballed" these gentlemen, the censure would have been merited; but as it requires the votes of four-fifths of the members to elect honorary members, it is very plain that, if even one-fifth of them chose to be eccentric or ungrateful, or both, and secured, as in this case, the vote of one or two more similarly disposed, the names of any gentlemen, however distinguished, would be rejected and dishonoured.

The rejection of Bernard and Brown-Séquard is easily explained. It was the result of an accident, Professor Bennett having been first voted for. The great majority of the members, indignant at the success of the anti-Bennett clique, had no other way of expressing their indignation at their doings than to refuse to elect any other person when such a man as Professor Bennett had been rejected. They would most willingly have voted for Bernard and Brown-Séquard had the name of Bennett been respected. It is right that all this should be known in order to clear the members from the charge of ingratitude, which is even worse than that of eccentricity. Believe me, Sir, yours respectfully,

Edinburgh, March, 1857. L.R.C.S.E.

P.S. - Since writing the above, I have been informed that the votes of five-sixths of the members are requisite in order to elect an extraordinary member.

\section{MEDTCAL CATALOGUES.} To the Editor of The LAircet.

SIR, - The courteous letter of your correspondent, "Chirurgus Nosocomialis," in your last number demands a reply.

It points out two practical suggestions for the improvement of my Catalogue: the first, that, for more easy reference, the author's name should be classified according to the subjects treated on, and not, as at present, in the alphabetical order of names; the second, that the date of publication be appended to each work.

The former suggestion shall be acted upon in the next issue of my Catalogue, which will appear in the ensuing autumn. The latter, I confess, I have not the courage to adopt. It is my business to make the sale of medical books as effective as possible, and the many new editions appearing annually prove the success of my publications generally. Some works of admitted standard authority have a limited sale, and as a new edition cannot appear before the existing one is sold, I fear the appended date would in some instances prejudice the sale, and thus retard the progress of medical science by postponing the new edition, - a contingency which, I am sure, your correspondent no less than myself would deplore.

I may just add, that I believe in no instance has a publisher's catalogue appeared with the dates affixed, as a reference to those of Messrs. Murray, Longman and Co., J. W. Parker and Son, \&c. \&c., will prove.

I am, Sir, your obedient servant, New Burlington-steet, March, 1857 . 33 